\title{
Study Subject Nuclear Medicine Report
}

National Cancer Institute

\section{Source}

National Cancer Institute. Study Subject Nuclear Medicine Report. NCI Thesaurus. Code

C115513.

Records pertaining to the findings from a study subject's nuclear medicine images. 